\title{
Role and Outcomes of Laparoscopic Cholecystectomy
}

\author{
Debnath $\mathrm{BC}^{* *}$, Ghosh $\mathrm{A}^{2}$, Chowdhury $\mathrm{AK}^{3}$, Jahangir $\mathrm{R}^{4}$, Alam $\mathrm{F}^{5}$, Joarder $\mathrm{PAI}^{6}$, Alam TAHM
}

${ }^{1}$ Dr. Bidyut Chandra Debnath, Assistant Professor(r/s), Department of surgery, Bangabandhu Sheikh Mujib Medical University (BSMMU), Dhaka, Bangladesh

${ }^{2}$ Dr. Abanti Ghosh, Lecterur Physiology, Mugda Medical College, Dhaka, Bangladesh

${ }^{3}$ Dr.Abul Kalam Chowdhury, Associate Professor, Department of surgery, BSMMU, Dhaka, Bangladesh

${ }^{4}$ Dr. Rana Jahangir, Medical Officer, Department of surgery, BSMMU, Dhaka, Bangladesh

${ }^{5}$ Dr. FerdousAlam, Associate Professor, Department of surgery, BSMMU, Dhaka, Bangladesh

${ }^{6}$ Professor Aminul Islam Joarder, Department of surgery, BSMMU, Dhaka, Bangladesh

${ }^{7}$ Professor AHM Towhidul Alam, Chairman \& Head, Department of surgery, BSMMU, Dhaka, Bangladesh

DOI: $10.36347 /$ sjams.2021.v09i01.016

| Received: 17.12.2020 | Accepted: 26.12.2020 | Published: 16.01.2021

*Corresponding author: Dr. Bidyut Chandra Debnath

Abstract

Original Research Article

Introduction: Laparoscopic cholecystectomy (LC) speaks to a huge change in the administration of gallbladder diseases and it is the most regularly performed surgery of the biliary related tract.1 It is considered as the highest quality level therapy for cholelithiasis. It is the gold standard treatment. Objective: The aim of this study is to identify role and outcomes of Laparoscopic Cholecystectomy. Methods: The study procedure included ultrasonography, which was routinely performed on all patients to confirm the clinical diagnosis of cholelithiasis with number of stones, gallbladder wall thickness, pericholecystic collection, sizes, and diameter of common bile duct.LC was performed using the standard four port technique and pneumoperitoneum was created using Hasson or Veress needle technique. Results: In the study, we found that the indications of surgery were symptomatic chronic calculous cholecystitis in $90.55 \%$ patients, which is the major indication of surgery. Chronic acalculouscholecystitis were found in $2.35 \%$, acute cholecystitis was found in $4.80 \%$, and gall bladder polyp was found $2.40 \%$ of the patients. The mean operative time was 63.91 \pm 20.01 (range: 50-90 min) and intra-abdominal drain was placed in $13(18.57 \%)$ patients. Conclusion: Increasing operative time was associated with increased odds of complications and, therefore, it appears that speed may matter in laparoscopic surgery.

Keywords: Operative time; Laparoscopic surgery; Outcome.

Copyright $(\odot) 2021$ The Author(s): This is an open-access article distributed under the terms of the Creative Commons Attribution 4.0 International License (CC BY-NC 4.0) which permits unrestricted use, distribution, and reproduction in any medium for non-commercial use provided the original author and source are credited.

\section{INTRODUCTION}

Laparoscopic cholecystectomy (LC) speaks to a huge change in the administration of gallbladder diseases and it is the most regularly performed surgery of the stomach related tract [1]. It is considered as the highest quality level therapy for cholelithiasis. It supplanted open cholecystectomy as the best option of treatment for gallstones and irritation of the gallbladder. It was made without precedent for 1987 by Muret. Notwithstanding many alternate strategies, LC is as yet the highest quality level for suggestive gallstone disease [2].The benefits of the laparoscopic approach are less postoperative sequelae, limited emergency clinic stay, quicker recuperation, improved corrective outcomes, less complications, for example, infection, grips, continuation of disease and low expectation to absorb treatment and, it is better than other created procedures in view of financial preferred position [3-5].

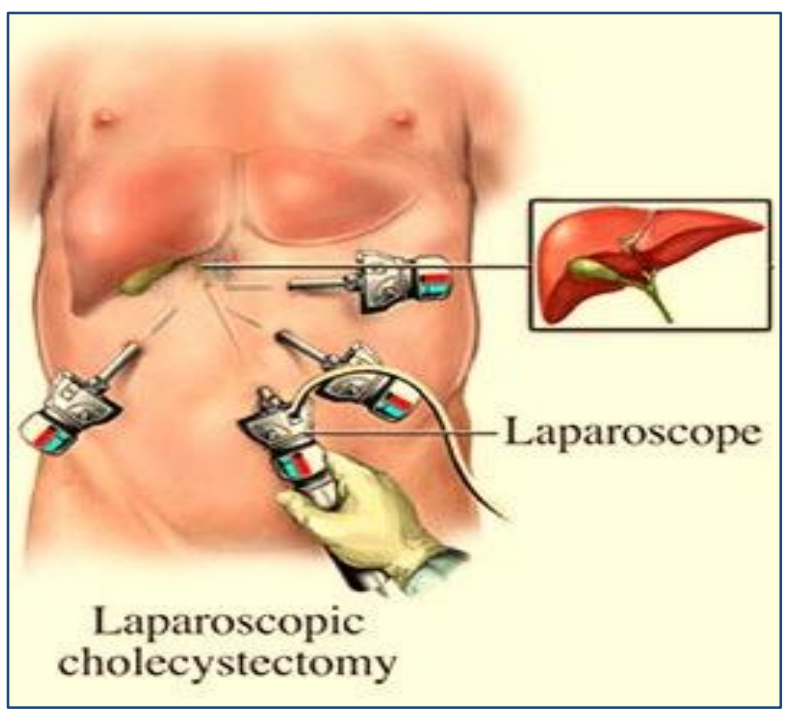

Fig-1: Laparoscopic Cholecystectomy. (Source: Google.com) 
The outcome of laparoscopic cholecystectomy in the previous studies have been assessed by many different measures: conversion rates, bile duct injuries, morbidity and mortality. However, there still remains debate which method should be preferredover other similar surgical methods to reflect surgical quality; as the various measures have strengths and weaknesses [6].

\section{Methodology And Materials}

The study was a Retrospective study conducted Bangabandhu Sheikh Mujib Medical University (BSMMU), Dhaka, Bangladesh. From February 2014 to February 2015. Study samples 70. Ultrasonography was routinely performed on all patients to confirm the clinical diagnosis of cholelithiasis with number of stones, gall-bladder wall thickness, pericholecystic collection, sizes, and diameter of common bile duct. LC was performed using the standard four port technique and pneumoperitoneum was created using Hasson or Veress needle technique. During this study period, five consultant surgeons with vast experience in the field of laparoscopy performed. After surgery, patients were followed up after one week, one month and three months. Exclusion criteria was Defective mental health and other major or incurable diseases

\section{RESULTS}

The maximum number patients $(44.29 \%)$ were in the age group of $31-42$ years. $37.14 \%$ patients were in 18-30 years' age group, $10 \%$ were in $18-30$ years' age group, and only $8.57 \%$ were in $\leq 55$ years' age group (Table 1). Figure-2 indicates the sex distribution of the patients. Among all studied patients $17.1 \%$ were male and $82.9 \%$ were female. Figure-3 shows the indications of surgery distribution among the patients. The indications of surgery were symptomatic chronic calculouscholecystitis in $90.55 \%$ patients, which is the major indication of surgery. Chronic acalculous cholecystitis was found in $2.35 \%$, acute cholecystitis was found in $4.80 \%$, and gall bladder polyp was found $2.40 \%$ of the patients. Table- 2 shows the operating time range of the samples which indicates the pre-operative conditions of the patients. The mean operative time was 63.91 \pm 20.01 (range: 50-90 $\mathrm{min}$ ) and intra-abdominal drain was placed in $13(18.57 \%)$ patients.

Table-1: Age Distribution of the Samples $(n=70)$

\begin{tabular}{|l|l|l|}
\hline Age Distribution (years) & $\mathbf{n = 7 0}$ & $\mathbf{\%}$ \\
\hline 18 years to 30 years & 26 & 37.14 \\
\hline 31 years to 42 years & 31 & 44.29 \\
\hline 43 years to 54 years & 7 & 10.00 \\
\hline$\leq 55$ years & 6 & 8.57 \\
\hline Total & 70 & 100.00 \\
\hline
\end{tabular}

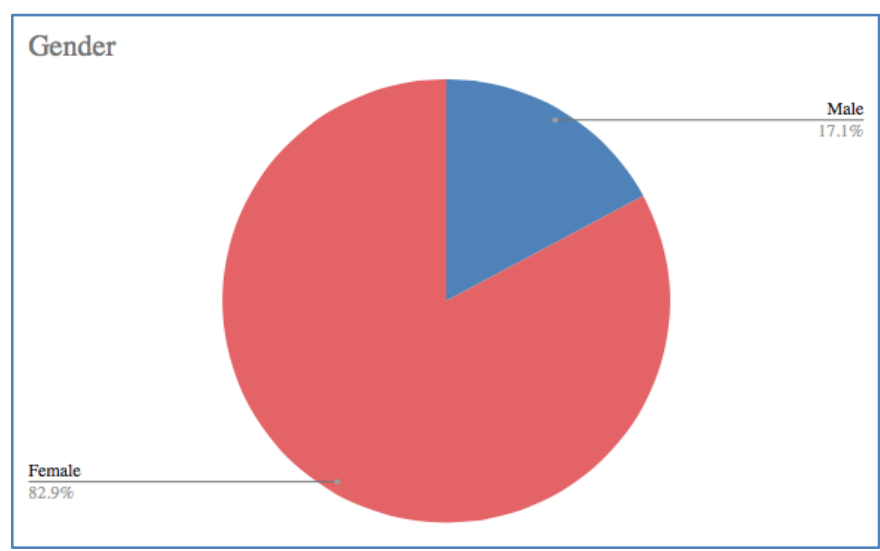

Fig-2: Sex Distribution of the Samples. $(n=70)$

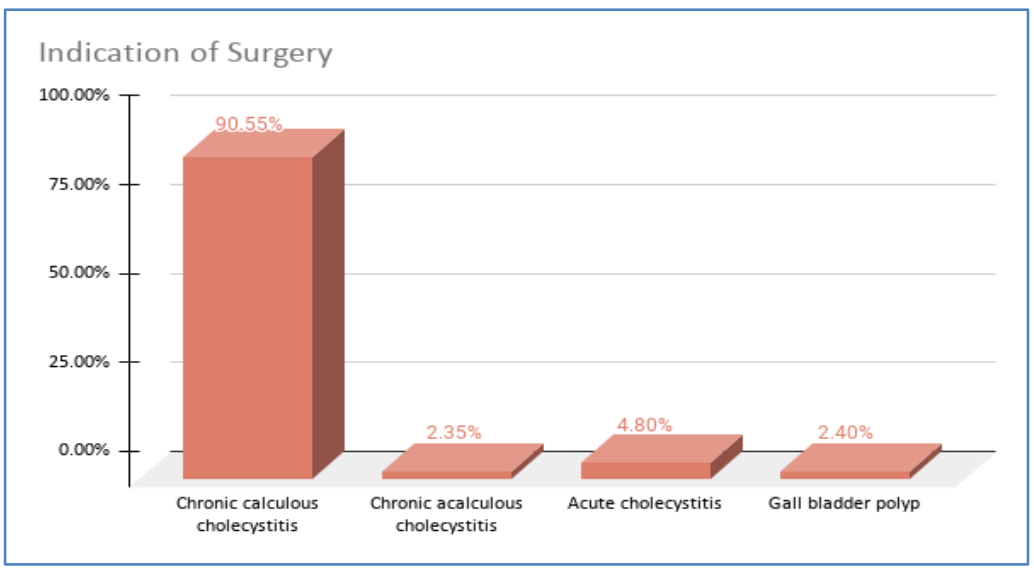

Fig-3: Indications of Surgery $(n=70)$ 
Debnath BC et al; Sch J App Med Sci, Jan, 2021; 9(1): 82-85

Table-2: Operative time $(\min )(\mathbf{N}=70)$

\begin{tabular}{|l|l|}
\hline Operative Time & \% \\
\hline 60 and below & $44(63 \%)$ \\
\hline $61-79$ & $17(24.29 \%)$ \\
\hline 80 and above & $9(12.86 \%)$ \\
\hline Drainage & $13(18.57 \%)$ \\
\hline Hospital stay mean \pm SD (range) in days & $4.1 \pm 1.1(1-12)$ \\
\hline
\end{tabular}

\section{DisCUSSION}

Gallstone disease is a worldwide medical issue. The rate is $10-20 \%$ of the entire adult group of populace, LC has now supplanted open cholecystectomy as the best option of treatment for gallstones, LC is acted in over $90 \%$ of elective cholecystectomies and $70 \%$ of crisis cholecystectomies making LC one of the most habitually performed surgeries on the planet [7]. In the previous studies, it was noted that the pace of transformation from LC to open cholecystectomy differs from 2.6 to $7.7 \%[8,9]$ conversion brings about a critical change in the result of the patients because of higher occurrence of postoperative confusions and longer clinic stay. In the study, we found that the indications of surgery were symptomatic chronic calculouscholecystitis in $90.55 \%$ patients, which is the major indication of surgery. Chronic were found in $2.35 \%$, acute cholecystitis was found in $4.80 \%$, and gall bladder polyp was found $2.40 \%$ of the patients. Biliary wounds keep on being a critical issue following LC; most examinations indicated an expansion in the frequency of these wounds. With the coming of laparoscopy, the pace of genuine bile conduit wounds after cholecystectomy expanded up to $0.8 \%$, while the one identified with the open course stayed between $0.2-0.3 \%$ [10]. The operative time in our operating time range of the samples which indicates the pre-operative conditions of the patients. The mean operative time was $63.91 \pm 20.01$ (range: $50-90 \mathrm{~min}$ ) and intra-abdominal drain was placed in $13(18.57 \%)$ patients. This finding was coordinate with different investigations. This show the medical procedure technique is productive and less time-consuming than opensurgeries. Surgical site infection is altogether lower after laparoscopic medical procedure contrasted with open a medical procedure and patients treated with laparoscopy were $72 \%$ more averse to encounter a careful site infection $[11,12]$. We experienced 6 instances of infection, which is reliable with the frequency in the previous studies.

\section{CONCLUSION}

Out study concluded that the role of LC is indispensable as a Gallbladder diseases surgical methods. Laparoscopic cholecystectomy can be done in all types of Gall Bladder pathology including acute cholecystitis where expertise and facilities are available. This was a Retrospective type of study in a single community with comparatively small number of sample size. So, the study result may not reflect the exact scenarios of the whole country. However, further studies on more samples are needed to have a definitive conclusion.

Funding: No funding sources

Conflict of interest: None declared

\section{REFERENCES}

1. Karimian F, Aminian A, Mirsharifi R, Mehrkhani F. Surgical options in the management of cystic duct avulsion during laparoscopic cholecystectomy. Patient Safety in Surgery. 2008; 2:17-17.

2. Duman K, Sezer K.H, Yilmaz F, Akin ML. The clinical outcome of traditional laparoscopic Cholecystectomy. Gaziantep Med J. 2013;19(1):35-39.

3. Ivatury SJ, Louden CL, Schwesinger WH. Contributing factors to postoperative length of stay in laparoscopic cholecystectomy. JSLS. 2011; 15:174-178.

4. Nuzzo G, Giuliante F, Giovannini I, Ardito F, D'Acapito F, Vellone M. Bile duct injuryduring laparoscopic cholecystectomy: results of an Italian national survey on cholecystectomies. Arch Surg. 2005; 140:986-992.

5. Tiwari MM, Reynoso JF, High R, Tsang AW, Oleynikov D. Safety, efficacy, and costeffectiveness of common laparoscopic procedures. SurgEndosc. 2011;25:1127-1135.

6. Veen E.J, Bik M, Janssen-Heijnen M.L.G, De Jongh M, Roukema A.J. Outcome measurement in laparoscopic cholecystectomy by using a prospective complication registry: results of an audit. International Journal for Quality in Health Care. 2008;20(2):144-151.

7. Sheffield KM, Ramos KE, Djukom CD, Jimenez CJ, Mileski WJ, Kimbrough TD, CM Townsend, Jr., Riall TS. Implementation of a critical pathway for complicated gallstone disease: translation of population-based data into clinical practice. J Am Coll Surg. 2011;212:835-843.

8. Ballal M, David G, Willmott S, Corless DJ, Deakin M, Slavin JP. Conversion after laparoscopic cholecystectomy in England. SurgEndosc. 2009;23:2338-2344.

9. Zhang WJ, Li JM, Wu GZ, Luo KL, Dong ZT. Risk factors affecting conversion in patients undergoing laparoscopic cholecystectomy. Anz J Surg. 2008; 78:973-976. 
10. Wu YV, Linehan DC. Bile duct injuries in the era of laparoscopic cholecystectomies. Surg Clin North Am. 2010;90:787-802.

11. Passos MA, Portari-Filho PE. Antibiotic prophylaxis in laparoscopic cholecistectomy: is it worth doing. Arq Bras Cir Dig. 2016;29(3):170172.

12. Varela JE, Wilson SE, Nguyen NT. Laparoscopic surgery significantly reduces surgical-site infections compared with open surgery. SurgEndosc. 2010;24(2):270-276. 